\title{
Estrogen Receptor $\beta$ of Host Promotes the Progression of Lung Cancer Brain Metastasis of an Orthotopic Mouse Model
}

\author{
Lei Xu' ${ }^{1}$, Guang Gao ${ }^{1}$, Jiangong Ren ${ }^{1}$, Fei Su${ }^{2}$, Weihua Zhang ${ }^{1 *}$ \\ ${ }^{1}$ Department of Biology and Biochemistry, University of Houston, Houston, USA; ${ }^{2}$ Center for Nuclear Receptors and Cell Signaling, \\ College of Natural Sciences and Mathematics, University of Houston, Houston, USA. \\ Email: *wzhang13@uh.edu
}

Received July $19^{\text {th }}, 2012$; revised August $23^{\text {rd }}, 2012$; accepted September $8^{\text {th }}, 2012$

\begin{abstract}
Estrogen receptors $(\mathrm{ER} \alpha$ and $\mathrm{ER} \beta)$ in the brain play critical roles in maintaining brain tissue homeostasis and in tissue repair after injury. Growth of cancer metastasis in the brain is a constant damaging process. The role of ERs of the host in the progression of cancer brain metastasis is unknown. To determine the role of ER $\beta$ of host in the progression of lung cancer brain metastasis, we used an isogenic murine lung cancer cell line, Lewis lung carcinoma cells (3LL), to produce orthotopic lung cancer brain metastases in wild type and $\operatorname{ER} \beta$ knockout $\left(\operatorname{ER} \beta^{-1}\right)$ mice. In the wild type mice, we found that $\mathrm{ER} \alpha$ and $\mathrm{ER} \beta$ appeared in the tumor associated reactive astrocytes at $24 \mathrm{hr}$ after injection of tumor cells, and $\mathrm{ER} \beta$ remained thereafter while ER $\alpha$ disappeared after 1 week. The metastasis bearing ER $\beta^{-/-}$mice survived significantly longer than the wild type mice. To further test the role of $\operatorname{ER} \beta$ of reactive astrocytes in the survival of cancer cells, we knocked down ER $\beta$ in cultured actrocytes using shRNA and performed 3D co-culture with 3LL cells in the presence/absence of chemotherapeutic agents, oxaliplatin and 5-fluorouracil. We found that loss of ER $\beta$ in astrocytes significantly reduced the survivability of $3 \mathrm{LL}$ cells co-cultured with astrocytes. It is concluded that ER $\beta$ of host, especially ER $\beta$ in reactive astrocytes, promotes the progression of lung cancer brain metastasis and ER $\beta$ might be a potential therapeutic target for lung cancer brain metastasis.
\end{abstract}

Keywords: Lung Cancer; Brain Metastasis; Reactive Astrocytes; Estrogen Receptor $\beta$

\section{Introduction}

The development of brain metastasis in lung cancer patients is highly fatal. In the USA, $50 \%-60 \%$ of lung cancer patients will develop brain metastasis [1]. The median survival of these patients is 2 - 3 months and aggressive radiotherapy combined with chemotherapy may prolong it to a median of 6 - 8 months [2]. Traditionally the resistance of brain metastasis to chemotherapy has been attributed to the blood-brain-barrier (BBB) [3]. However, it has been found that tumor cells in brain metastasis produce VEGF/VPF which renders the BBB permeable [4]. There are two other non-mutually exclusive mechanisms that may be responsible for the chemoresistance of brain metastases. One is that the cancer cells that can grow in the brain environment are a selected subpopulation of cells that are chemoresistant; the other possibility is that the brain microenvironment confers drug resistance to tumor cells.

In the brain parenchyma, there are three major popula-

\footnotetext{
${ }^{*}$ Corresponding author.
}

tions of cells, vascular cells, neuronal cells and glial cells. The growth of brain metastasis is a process of combination of tissue destruction induced by invading tumor cells and reactive alterations occurring around the metastases, which results in a series of pathological microenvironmental changes. One of the most dramatic reactions in the peritumoral region of brain metastasis is astrocytosis [5], an increase in the number of reactive astrocytes due to the destruction of nearby brain tissue. The physiological function of reactive astrocytes is to repair/rescue damaged tissues by providing pro-survival inputs and scar formation [6]. A tumor, "the wound that never heals" [7], growing in the brain induces astrocytosis $[8,9]$ similar to other types of physical injury $[10,11]$. A pro-survival role of reactive astrocytes to brain metastasis, as they have with regard to the neurons, has been proposed [12].

Estrogen is neuroprotective and facilitates neuron recovery from injury [13]. It has been found that astrocytes are the major mediator of estrogen's neuroprotective effect [14]. The genomic functions of estrogen are mediated by its receptors, estrogen receptor $\alpha(\mathrm{ER} \alpha)$ and 
$(\operatorname{ER} \beta)$. Neither $\operatorname{ER} \alpha$ nor $\operatorname{ER} \beta$ can be detected by immunohistochemistry in astrocytes of intact brain, however, both receptors are significantly upregulated in the reactive astrocytes following brain injuries $[15,16]$, and both receptors are required to carry out estrogen's protective effect [17].

In this study, we used an isogenic murine lung cancer cell line, 3LL, to produce orthotopic brain metastases in the brains wild type $\left(\mathrm{ER} \beta^{+/+}\right)$and $\mathrm{ER} \beta$ knockout $\left(\mathrm{ER} \beta^{-/-}\right)$ male mice, and investigated the role of ER $\beta$ of host in the progression of brain metastasis of lung cancer. In addition, we also determined the effects of $\operatorname{ER} \beta$ of astrocytes on the survival of co-cultured 3LL cells.

\section{Materials and Methods}

\subsection{Antibodies}

Goat polyclonal antibody against glial fibrillary acidic protein (GFAP) was from Santa Cruz. Homemade chicken anti-ER $\beta$ antibody, ER $\beta 503$, and rabbit anti-ER $\beta$ antibody, ER $\beta$-LBD, were described previously $[18,19]$. Rabbit polyclonal antibody against $\mathrm{ER} \alpha$ was from SantaCruz (\#MC20). Horseradish peroxidase conjugated and alkaline phosphatase conjutated secondary antibodies were from Sigma-Aldrich.

\subsection{Cells and Cell Culture}

Murine cell line, 3LL (Cat. CRL-1642), and astrocytes (Cat. CRL-2534) were purchased from American Type of Cell Culture (ATCC). Cells were cultured in Dulbecco's modified Eagle's medium (DMEM) containing $10 \%$ fetal bovine serum (FBS) in an incubator at $37^{\circ} \mathrm{C}$ supplied with $5 \% \mathrm{CO}_{2}$. For co-culturing $3 \mathrm{LL}$ cells and astrocytes, we first stably transfected green fluorescent protein (GFP) in to the 3LL cells, which allows us to differentiate cancer cells (GFP positive) from the co-cultured astrocytes (GFP negative). The 3D cell co-culture was performed with a seeding ratio of 3LL cells/astrocytes at 3:1 using the n3D cell culture system from Nano3D Biosciences (Houston, TX) according to the protocol provided by the manufacturer.

\subsection{Knocking down ER/ by shRNA}

The U6 promoter-driven shRNA expression vector (pRNAT-U6.1/Neo) from Genscript (Piscataway, NJ) was used to construct vectors expressing ER $\beta$ shRNA or scrambled control shRNA. The target sequence for ER $\beta$ was GTCCGCCTCTTGGAAAGCT, and the control sequence was GAACAATGTTGACCAGGTGA. Before co-culturing with $3 \mathrm{LL}$ cells, asctrocytes were transfected with either control shRNA or ER $\beta$ shRNA plasmids for $48 \mathrm{hr}$ using trasfection reagent Genjuice according to the manufacturer's instruction (Roche). Western Blot was used to determine the efficiency of ER $\beta$ shRNA.

\subsection{Western Blot Assay}

Cells were lysed for 30 minutes on ice in RIPA buffer (Sigma Aldrich, St. Louis, MO) supplemented with protease and phsophatase inhibitors. The concentrations of the protein samples were measured using the Qubit flourometer (Invitrogen, Carlsbad, CA) and equal amounts of protein samples were loaded onto a 10\% SDS-PAGE gel and transferred to a PVDF membrane. Membranes were incubated in $5 \%$ milk to block the non specific binding sites for 30 minutes and incubated with optimized concentrations of primary antibody $\operatorname{ER} \beta$-LBD at 1:1000 dilutions at $4^{\circ} \mathrm{C}$ overnight. After washing with $3 \times$ PBS, membranes were incubated with horseradish peroxidase conjugated secondary antibodies (Santa Cruz Biotechnology, Santa Cruz, CA) at 1:3000 dilutions for 1 hour at room temperature. Luminescent signals were detected using enhanced luminescence kit (Pierce ThermoScientific, Rockford, IL) and exposed to X-ray films (VWR, Bridgeport, NJ).

\subsection{Cell Survival Assay}

Co-cultured 3LL cells and astrocytes were treated with 5 -fluorouracil (5-FU, $30 \mu \mathrm{g} / \mathrm{ml})$ or oxaliplatin $(50 \mu \mathrm{g} / \mathrm{ml})$ the $24 \mathrm{hr}$ after the establishment of 3D co-culture. Control cells were treated with an equal volume of vehicle. The treatments lasted for $12 \mathrm{hr}$ before cells were harvested for trypan blue uptake assay. The dead cancer cells were identified by dual positivity of trypan blue and GFP signals under an inverted fluorescent microscope. Cell viability was estimated basing on the percentage of GFP positive dead cells from triplicate samples of each experimental group.

\subsection{Animals and Intracarotid Artery Injection of Tumor Cells}

Wild type and heterozygous of $\operatorname{ER} \beta$ knockout mice $\left(\mathrm{ER} \beta^{+/-}\right)$were purchased from the Jackson Laboratory (Bar Harbor, Maine). ER $\beta^{-/}$mice were produced by breeding the $\mathrm{ER}^{+-}$pairs at the animal facility of University of Houston. Male mice of wild type and ER $\beta^{-/-}$at the age of 3 months were used for injection of $3 \mathrm{LL}$ cells via the intracarotid artery into the brain according the protocol described previously [20]. In brief, Mice were anesthetized by injection (i.p.) of a mixture of ketamine (100 $\mathrm{mg} / \mathrm{kg}$ ) $/ x y l a z i n e(5 \mathrm{mg} / \mathrm{kg}$ ), washed with $70 \%$ alcohol, and restrained to a cork board in a back position and placed under a dissecting microscope. The head of animal was stabilized with a rubber band placed between 
the teeth of the upper jaw. The hair over the trachea is shaved, the neck washed with $70 \%$ alcohol and the skin cut by a mediolateral incision. After blunt dissection, the trachea was exposed and the muscles were separated to expose the carotid artery which was then separated from the vagal nerve. The artery was prepared for injection at a point distal to the point of division into the internal and external carotid arteries. A ligature of 5 - 0 silk suture was placed and tied in a position proximal to the injection site. The artery was nicked with a pair microscissors and a plastic cannula was inserted into the blood vessel lumen. The cells $(250,000$ cells in $20 \mu \mathrm{l})$ were injected slowly. The cannula was removed, and the distal ligature was tightened and the skin was closed by a tissue clamp.

\subsection{Immunohistochemistry}

For immunoperoxidase staining with diaminobenzidine (DAB) labeling, tissue sections were deparaffinized in xylene and rehydrated in a graded series of alcohol and PBS. Antigen retrieval was performed using heated citrate buffer. Endogenous peroxidase activity was blocked with 3\% hydrogen peroxide in methanol. Samples were incubated in a blocking solution (5\% donkey serum in PBS) for 1 hour at room temperature and then overnight at $4{ }^{\circ} \mathrm{C}$ with the primary antibodies diluted in the blocking solution (ER $\alpha$ antibody was diluted at 1:200; ER $\beta 503$ antibody was diluted at 1:50; GFAP antibody was diluted at 1:200). After three washes in PBS, samples were incubated with a biotinylated goat anti-rabbit secondary antibody (1:500) for 1 hour at room temperature and then washed thoroughly. An ABC staining kit was used for chromogenesis. Slides were then briefly counterstained with hematoxylin and mounted. For double staining using horseradish peroxidase conjugated (1:500) and alkaline phosphatase conjutated (1:500) secondary antibodies, slides incubated with a mixture of primary antibodies of either ER $\alpha$ (MC-20, rabbit origin)/GFAP (goat origin) or ER $\beta 503$ (chicken origin)/GFAP (goat origin) were washed with PBS and subsequently incubated with a mixture of respective secondary antibodies. Signal of peroxidase was first developed, then the slides were washed with PBS before the development of alkaline phosphatase signal. Slides were then briefly counterstained with hematoxylin and mounted. Staining Images were taken using a Nikon histology imaging microscope.

\subsection{Statistical Analyses}

Student t-test with two tails and equal variance was used to compare the values of two experimental groups and a $P$ value less than 0.05 is considered as statistically significance.

\section{Results}

\subsection{Characterization of Changes of ER $\alpha$ and $E R \beta$ in the Brain during the Development of Lung Cancer Brain Metastasis}

The isogenic murine lung cancer cell line, 3LL (developed spontaneously in C57/BL6 mice), allows us to study the pathogenic progression of lung cancer brain metastasis in immnocompetent mice of the same strain. To gain insights into the role of ERs of the brain in the progression of lung cancer brain metastasis, by immunohistochemical co-staining, we profiled the expression of $\mathrm{ER} \alpha$ and $\mathrm{ER} \beta$ in tumor associated reactive astrocytes (identified by immnohistochemical staining of glial fibrillary acidic protein, GFAP) in the brain tissues of wild type male mice collected at a series of time points after injection of 3LL cells into the brain via intracarotid artery injection. Tissues were collected at $24 \mathrm{hr}, 1 \mathrm{wk}$, and 3 wk after tumor injection. As shown in Figure 1, the tumor associated reactive astrocytes are positive for ER $\alpha$ and $\operatorname{ER} \beta$ at the $24 \mathrm{hr}$ time point, ER $\alpha$ disappeared at 1 wk while ER $\beta$ remained. These data suggest that both $\mathrm{ER} \alpha$ and $\mathrm{ER} \beta$ are involved in the early phase of astrocyte activation and $\mathrm{ER} \beta$ but not $\mathrm{ER} \alpha$ is involved in sustaining the functions of reactive astrocytes in the process of tumor growth.

\subsection{Astrocytic ER $\beta$ Is Critical for the Pro-Survival Function of Astrocytes in Vitro}

To further determine the pro-survival role of $\operatorname{ER} \beta$ in astrocytes, we performed survival analyses on $3 \mathrm{LL}$ cells co-cultured with astrocytes with/without knockdown of ER $\beta$ by shRNA. We used Western blot and immunocytochemistry to determine the efficiency of ER $\beta$ shRNA. As shown in Figure 2(a), astrocytes transfected with

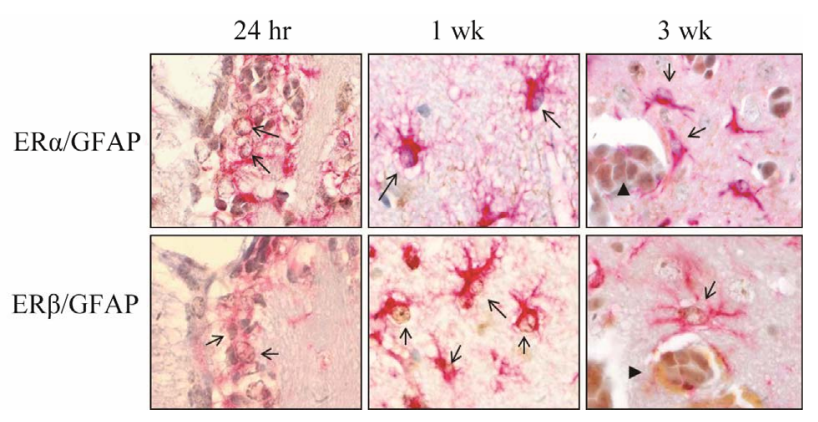

Figure 1. Immunochemical double staining of ER $\alpha /$ GFAP and $E R /$ /GFAP of tumor associated reactive astrocytes in the brain of wild type mice. Immunoperoxidase staining with diaminobenzidine (DAB) labeling (brown color) was used for $E R \alpha$ and ER $\beta$, and alkaline phosphatase staining was used for GFAP (pink color). Arrows indicate nuclei of reactive astrocytes. Arrow heads indicate tumor cells. Bar = $20 \mu \mathrm{m}$. 
(a)

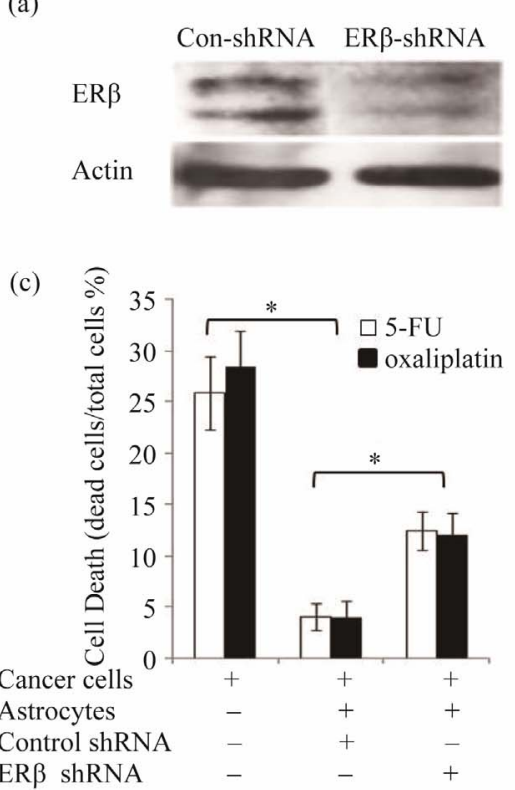

(b)

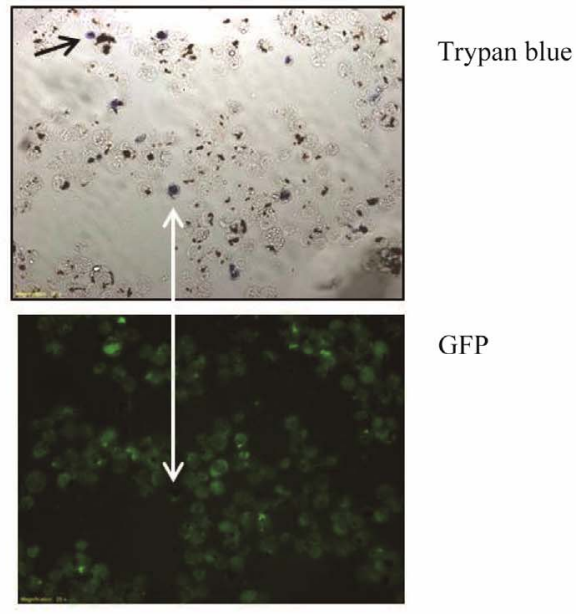

Figure 2. Loss of ER $\beta$ in astrocytes reduced the pro-survival function of astrocytes to tumor cells. (a) Western blot analysis of ER/ expression in astrocytes trasnfected with control-shRNA or ER/-shRNA. Beta actin was used as a loading control; (b) Trypan blue uptake assay of cell viability of GFP labeled 3LL cells co-cultured with astrocytes. Image of normal light (to visualize trypan blue staining, arrows) and image of fluorescent (to visualize GFP signal) were taken for each field of observation, and total GFP positive cells (cancer cells) and trypan blue and GFP dual positive cells (double-head arrow) were counted. The single-head arrow indicates a dead astrocyte (trypan blue positive and GFP negative); (c) Quantification of cell death of 3LL cells cultured alone and co-cultured with astrocytes treated with control shRNA or ERß shRNA. Triplicate samples were used in each group. Asterisk indicates statistically significant between the linked groups (error bars $=$ standard deviation, $\mathrm{P}<\mathbf{0 . 0 5}$ ).

ER $\beta$ shRNA had significantly lower levels of ER $\beta$ as compared to the control cells. To determine the effect of astrocytes on cancer cells' survival, we stably expressed green fluorescent protein (GFP) in the 3LL cells, which allows us to distinguish 3LL cells from the co-cultured GFP negative astrocytes. We transfected astrocytes with either $\mathrm{ER} \beta$-shRNA or control-shRNA $48 \mathrm{hr}$ prior to coculture, we then co-cultured $3 \mathrm{LL}$ cells with these astrocytes using the $\mathrm{n} 3 \mathrm{D}$ co-culture system in the presence/ absence of 5-fluorouracil or oxalaplatin for $24 \mathrm{hr}$. After treatments, cells were trypsinized, stained with trypan blue, plated on tissue slides and sealed with cover slides. Green fluorescent images of GFP signal and normal light images of trypan blue signal were taken for each field of observation. Dead cancer cells (positive for both GFP and trypan blue) and live cancer cells (positive for GFP only) (Figure 2(b)) were counted in 3 fields of each sample (there were 3 samples in each group) under an upright fluorescent microscope. As shown in Figure 2(c), co-culturing with astrocytes protected cancer cells from the toxicities of both drugs, and loss of ER $\beta$ significantly reduced the pro-survival effects of astrocytes. These data suggest that ER $\beta$ in the cancer cell associated astrocytes is pro-survival to the cancer cells.

\subsection{Loss of ER $\beta$ in the Host Prolonged Lives of Mice Bearing Lung Cancer Brain Metastasis}

To determine the role of $\operatorname{ER} \beta$ of host in the progression of brain metastasis, we injected tumor cells into the brains of age matched wild type and ER $\beta$ knockout male (C57/BL6 background). Loss of physical balance was used as a sign of termination of experiment. When the survival curves of these mice were compared, it was found that the ER $\beta$ knockout mice survived significantly longer that the wild type, the median survival time for the wild type mice was 22 days and for the $\operatorname{ER} \beta$ knockout mice was 34 days (Figure 3). These data suggest that $\mathrm{ER} \beta$ of the host is involved in promoting the disease progression of lung cancer brain metastasis.

\section{Discussion}

Cancer brain metastasis is notoriously resistant to conventional therapies. Increasing attentions have been drawn to the contribution of brain microenvironment. Studies have found that reactive astrocytes are pro-survival to tumor cells $[21,22]$. The molecular mechanisms by which reactive astrocytes provide tumor cells with survival support are being revealed. It has been found that physi- 


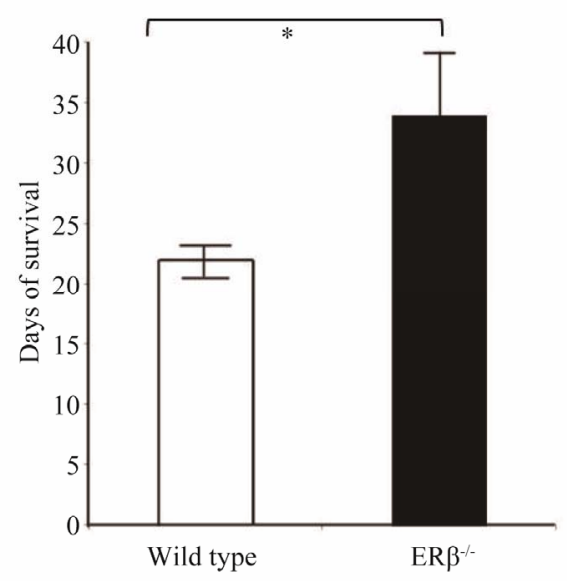

Figure 3. Brain metastases bearing ER/ knockout mice survived longer than the wild type mice. The median survival time of wild type mice $(n=4)$ was 22 days, and the median survival time of the ER $\beta$ knockout mice $(n=3)$ was 34 days. Asterisk indicates statistically significant between the linked groups (error bars = standard deviation, $\mathbf{P}<$ 0.007).

cal contact between tumor cells and reactive astrocytes is required for astrocytes to provide survival support to tumor cells [21,22]. Targetable mechanisms are highly desired. Our study, for the first time, found that $\operatorname{ER} \beta$, a steroid hormone nuclear receptor, plays a key role in the pro-survival functions of tumor associated reactive astrocytes.

The differential upregulation of $\operatorname{ER} \alpha$ and $\operatorname{ER} \beta$ in the tumor associated astrocytes suggest that $\operatorname{ER} \alpha$ and $\operatorname{ER} \beta$ plays different roles in the biology of tumor associated reactive astrocytes. The quick up-regulation of $\operatorname{ER} \alpha$ and $\mathrm{ER} \beta$ after the inoculation of tumor cells indicates that both receptors are involved in the initiation process of astrocyte activation. The disappearance of ER $\alpha$ and continuous expression of $\operatorname{ER} \beta$ after 1 wk of inoculation of tumor cells suggest that reactive astrocytes undergo a significant genetic reprogram process in response to the invasion of cancer cells to the brain. The continuous pattern of $\operatorname{ER} \beta$ expression in the tumor associated reactive astrocytes indicates that $\mathrm{ER} \beta$ is involved in maintaining the function of astrocyte at its reactive status, which is supported by the in vitro cell co-culture data that loss of $\mathrm{ER} \beta$ significantly reduced the pro-survival function of astrocytes to tumor cells (Figure 2). The chemoprotective function of astrocytes has been demonstrated in various melanoma cells, breast cancer cells and lung cancer cells [23]. Establishment of gap junctions between cancer cells and astrocytes is required for astrocytes to provide cancer cells with survival support [22]. Although the exact molecular mechanisms by which astrocytes offer tumor cells with chemoresistant strength remain to be investigated, clues can be found from what is known about how reactive astrocytes protect neurons from insults [24,25]. Studies have found three major mechanisms by which reactive astrocytes provide neurons in damage with survival support, increased release of neurotrophic factors, increased release of glutathione, and enhanced energetic supply [10]. Reactive astrocytes secrete fibroblast growth factor 2 [26] and nerve growth factor [27], and glutathione promotes cell survival by reducing cellular oxidative stress. These secreted prosurvival factors do not depend on cell-cell contact to execute their functions. The enhanced energetic metabolism made in the reactive astrocytes deserves more attention from a cancer brain metastasis point of view. Reactive astrocytes have increased activities of fatty acid $\beta$-oxidation, glycolysis, pentose phosphate pathway and Krebs cycle [28,29]. These enhanced metabolisms generate increased amounts of intermediate metabolites that could be channeled to the neighboring cells in danger through gap junctions [30], which shall also increase the metabolic efficiency the neighboring cells to produce sufficient amount of ATP for sustaining survival in a hostile environment. Considering the death of cancer cells is also determined by the intracellular ATP levels [31] and the necessity of gap junctions between tumor cells and astrocytes to increase tumor cells' survival, the enhanced energetic supply from reactive astrocytes to tumor cells might be a major pro-survival mechanism offered by reactive astrocytes.

The orthotopic brain metastasis model used in this study, inoculating isogenic cancer cells into immunocompetent gene knockout animals, is novel at two folds. First, it overcomes the disadvantage of excluding the involvement of immune systems of immunodeficient animal models, such as SCID (severe combined immunodeficiency) or nude mice; second, it allows the study of the impact of a particular host gene on tumor progression. The $\operatorname{ER} \beta$ knockout mice used in this study is not tissue specific, we can't rule out the functions of $\operatorname{ER} \beta$ in the non-astrocytic cells are also involved in promoting the progression of brain metastasis. Astrocyte specific ER $\beta$ knockout is needed to conclusively define the role of astrocytic $\operatorname{ER} \beta$ in the progression of lung cancer brain metastasis. However, one of the advantages of using the whole body $\operatorname{ER} \beta$ knockout mice to test the impact of host $\mathrm{ER} \beta$ on tumor progression is that this model is more therapeutic relevant, i.e. if $\operatorname{ER} \beta$ was proven to be a therapeutic target for cancer brain metastasis, an $\operatorname{ER} \beta$ specific ligand that can inhibit function of $\operatorname{ER} \beta$ in reactive astrocytes can be administrated systemically.

\section{Acknowledgements}

This study was supported by a startup grant from the University of Houston to Z. W. Z. W. is also supported 
by grants from the American Cancer Society and the Department of Defense Prostate Cancer Research Program.

\section{REFERENCES}

[1] J. G. Santarelli, V. Sarkissian, L. C. Hou, A. Veeravagu and V. Tse, "Molecular Events of Brain Metastasis," Neurosurgical Focus, Vol. 22, No. 3, 2007, pp. 1-5. doi:10.3171/foc.2007.22.3.2

[2] E. C. Kaal, C. G. Niel and C. J. Vecht, "Therapeutic Management of Brain Metastasis," The Lancet Neurology, Vol. 4, No. 5, 2005, pp. 289-298. doi:10.1016/S1474-4422(05)70072-7

[3] G. Bernardo, Q. Cuzzoni, M. R. Strada, A. Bernardo, G. Brunetti, I. Jedrychowska, U. Pozzi and R. Palumbo, "First-Line Chemotherapy with Vinorelbine, Gemcitabine, and Carboplatin in the Treatment of Brain Metastases from Non-Small-Cell Lung Cancer: A Phase II Study," Cancer Investigation, Vol. 20, No. 3, 2002, pp. 293-302. doi:10.1081/CNV-120001173

[4] W. S. Kamoun, C. D. Ley, C. T. Farrar, A. M. Duyverman, J. Lahdenranta, D. A. Lacorre, T. T. Batchelor, E. di Tomaso, D. G. Duda, L. L. Munn, D. Fukumura, A. G. Sorensen and R. K. Jain, "Edema Control by Cediranib, a Vascular Endothelial Growth Factor Receptor-Targeted Kinase Inhibitor, Prolongs Survival Despite Persistent Brain Tumor Growth in Mice," Journal of Clinical Oncology: Official Journal of the American Society of Clinical Oncology, Vol. 27, No. 15, 2009, pp. 2542-2552.

[5] M. Zhang and Y. Olsson, "Hematogenous Metastases of the Human Brain-Characteristics of Peritumoral Brain Changes: A Review," Journal of Neuro-Oncology, Vol. 35, No. 1, 1997, pp. 81-89. doi:10.1023/A:1005799805335

[6] M. D. Laird, J. R. Vender and K. M. Dhandapani, "Opposing Roles for Reactive Astrocytes Following Traumatic Brain Injury," Neuro-Signals, Vol. 16, No. 2-3, 2008, pp. 154-164. doi:10.1159/000111560

[7] H. F. Dvorak, L. F. Brown, M. Detmar and A. M. Dvorak, "Vascular Permeability Factor/Vascular Endothelial Growth Factor, Microvascular Hyperpermeability, and Angiogenesis," The American Journal of Pathology, Vol. 146, No. 5, 1995, pp. 1029-1039.

[8] J. Z. Escalone, "Astrocytes in Brain Tumours. Differentiation or Trapping?" Histology and Histopathology, Vol. 9, No. 2, 1994, pp. 325-332.

[9] M. Zhang and Y. Olsson, "Reactions of Astrocytes and Microglial Cells around Hematogenous Metastases of the Human Brain Expression of Endothelin-Like Immunoreactivity in Reactive Astrocytes and Activation of Microglial Cells," Journal of the Neurological Sciences, Vol. 134, No. 1-2, 1995, pp. 26-32. doi:10.1016/0022-510X(95)00227-9

[10] C. Escartin and G. Bonvento, "Targeted Activation of Astrocytes: A Potential Neuroprotective Strategy," Molecular Neurobiology, Vol. 38, No. 3, 2008, pp. 231-241. doi:10.1007/s12035-008-8043-y

[11] J. L. Ridet, A. Privat, S. K. Malhotra and F. H. Gage,
"Reactive Astrocytes: Cellular and Molecular Cues to Biological Function," Trends in Neurosciences, Vol. 20, No. 12, 1997, pp. 570-577. doi:10.1016/S0166-2236(97)01139-9

[12] D. P. Fitzgerald, D. Palmieri, E. Hua, E. Hargrave, J. M. Herring, Y. Qian, E. Vega-Valle, R. J. Weil, A. M. Stark, A. O. Vortmeyer and P. S. Steeg, "Reactive Glia Are Recruited by Highly Proliferative Brain Metastases of Breast canCer and Promote Tumor Cell Colonization," Clinical \& Experimental Metastasis, Vol. 25, No. 7, 2008, pp. 799-810. doi:10.1007/s10585-008-9193-Z

[13] I. Azcoitia, D. Garcia-Ovejero, J. A. Chowen and L. M. Garcia-Segura, "Astroglia Play a Key Role in the Neuroprotective Actions of Estrogen," Progress in Brain Research, Vol. 132, 2001, pp. 469-478. doi:10.1016/S0079-6123(01)32096-4

[14] K. M. Dhandapani and D. W. Brann, "Role of Astrocytes in Estrogen-Mediated Neuroprotection," Experimental Gerontology, Vol. 42, No. 1-2, 2007, pp. 70-75. doi:10.1016/j.exger.2006.06.032

[15] D. Garcia-Ovejero, S. Veiga, L. M. Garcia-Segura and L. L. Doncarlos, "Glial Expression of Estrogen and Androgen Receptors after Rat Brain Injury," The Journal of Comparative Neurology, Vol. 450, No. 3, 2002, pp. 256271. doi:10.1002/cne.10325

[16] S. Sakuma, D. Tokuhara, H. Hattori, O. Matsuoka and T. Yamano, "Expression of Estrogen Receptor Alpha and Beta in Reactive Astrocytes at the Male Rat Hippocampus after Status Epilepticus," Neuropathology: Official Journal of the Japanese Society of Neuropathology, Vol. 29, No. 1, 2009, pp. 55-62.

[17] S. Suzuki, L. M. Gerhold, M. Böttner, S. W. Rau, C. D. Cruz, E. Yang, H. Zhu, J. Yu, A. B. Cashion, M. S. Kindy, I. Merchenthaler, F. H. Gage and P. M. Wise, "Estradiol Enhances Neurogenesis Following Ischemic Stroke through Estrogen Receptors Alpha and Beta," The Journal of Comparative Neurology, Vol. 500, No. 6, 2007, pp. 1064-1075. doi:10.1002/cne. 21240

[18] L. A. Helguero, M. H. Faulds, J. A. Gustafsson and L. A. Haldosén, "Estrogen Receptors Alfa (ERalpha) and Beta (ERbeta) Differentially Regulate Proliferation and Apoptosis of the Normal Murine Mammary Epithelial Cell Line HC11," Oncogene, Vol. 24, No. 44, 2005, pp. 6605 6616.

[19] C. Palmieri, G. J. Cheng, S. Saji, M. Zelada-Hedman, A. Warri, Z. Weihua, S. Van Noorden, T. Wahlstrom, R. C. Coombes, M. Warner and J. A. Gustafsson, "Estrogen Receptor Beta in Breast Cancer," Endocrine-Related Cancer, Vol. 9, No. 1, 2002, pp. 1-13. doi:10.1677/erc.0.0090001

[20] S. Yano, H. Shinohara, R. S. Herbst, H. Kuniyasu, C. D. Bucana, L. M. Ellis, D. W. Davis, D. J. McConkey and I. J. Fidler, "Expression of Vascular Endothelial Growth Factor Is Necessary but Not Sufficient for Production and Growth of Brain Metastasis," Cancer Research, Vol. 60, No. 17, 2000, pp. 4959-4967.

[21] S. J. Kim, J. S. Kim, E. S. Park, J. S. Lee, Q. Lin, R. R. Langley, M. Maya, J. He, S. W. Kim, Z. Weihua, K. 
Balasubramanian, D. Fan, G. B. Mills, M. C. Hung and I. J. Fidler, "Astrocytes Upregulate Survival Genes in Tumor Cells and Induce Protection from Chemotherapy," Neoplasia, Vol. 13, No. 3, 2011, pp. 286-298.

[22] Q. Lin, K. Balasubramanian, D. Fan, S. J. Kim, L. Guo, H. Wang, M. Bar-Eli, K. D. Aldape and I. J. Fidler, "Reactive Astrocytes Protect Melanoma Cells from Chemotherapy by Sequestering Intracellular Calcium through gap Junction Communication Channels," Neoplasia, Vol. 12, No. 9, 2010, pp. 748-754

[23] I. J. Fidler, "The Role of the Organ Microenvironment in Brain Metastasis," Seminars in Cancer Biology, Vol. 21, No. 2, 2011, pp. 107-112. doi:10.1016/j.semcancer.2010.12.009

[24] V. B. Mahesh, K. M. Dhandapani and D. W. Brann, "Role of Astrocytes in Reproduction and Neuroprotection," Molecular and Cellular Endocrinology, Vol. 246, No. 1-2, 2006, pp. 1-9. doi:10.1016/j.mce.2005.11.017

[25] M. V. Sofroniew, "Reactive Astrocytes in Neural Repair and Protection," The Neuroscientist: A Review Journal Bringing Neurobiology, Neurology and Psychiatry, Vol. 11, No. 5, 2005, pp. 400-407.

[26] P. J. Albrecht, J. P. Dahl, O. K. Stoltzfus, R. Levenson and S. W. Levison, "Ciliary Neurotrophic Factor Activates Spinal Cord Astrocytes, Stimulating Their Production and Release of Fibroblast Growth Factor-2, to Increase Motor Neuron Survival," Experimental Neurology, Vol. 173, No. 1, 2002, pp. 46-62. doi:10.1006/exnr.2001.7834
[27] M. Pehar, M. R. Vargas, P. Cassina, A. G. Barbeito, J. S. Beckman and L. Barbeito, "Complexity of AstrocyteMotor Neuron Interactions in Amyotrophic Lateral Sclerosis," Neuro-Degenerative Diseases, Vol. 2, No. 3-4, 2005, pp. 139-146. doi:10.1159/000089619

[28] C. Escartin, K. Pierre, A. Colin, E. Brouillet, T. Delzescaux, M. Guillermier, M. Dhenain, N. Déglon, P. Hantraye, L. Pellerin and G. Bonvento, "Activation of Astrocytes by CNTF Induces Metabolic Plasticity and Increases Resistance to Metabolic Insults," The Journal of Neuroscience: The Official Journal of the Society for Neuroscience, Vol. 27, No. 27, 2007, pp. 7094-7104.

[29] M. Gavillet, I. Allaman and P. J. Magistretti, "Modulation of Astrocytic Metabolic Phenotype by Proinflammatory Cytokines," Glia, Vol. 56, No. 9, 2008, pp. 975-989. doi:10.1002/glia.20671

[30] M. M. Froes, A. H. Correia, J. Garcia-Abreu, D. C. Spray, A. C. Campos de Carvalho and M. V. Neto, "Gap-Junctional Coupling between Neurons and Astrocytes in Primary Central Nervous System Cultures," Proceedings of the National Academy of Sciences of the United States of America, Vol. 96, No. 13, 1999, pp. 7541-7546. doi:10.1073/pnas.96.13.7541

[31] W. Lieberthal, S. A. Menza and J. S. Levine, "Graded ATP Depletion Can Cause Necrosis or Apoptosis of Cultured Mouse Proximal Tubular Cells," The American Journal of Physiology, Vol. 274, No. 2, 1998, pp. F315F327. 